- IEEE

EDUCON

Global Engineering Education Conference

\section{ONLINE........ \\ supported by cisco}

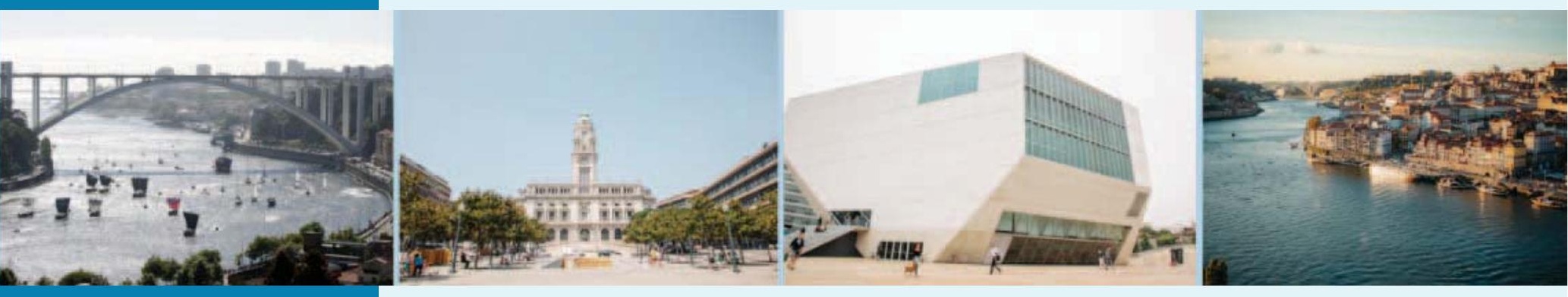

\title{
Proceedings of the
}

IEEE Global Engineering Education Conference (EDUCON 2020)

Engineering Education for the Future in a Multicultural and Smart World

\section{Editors}

Alberto Cardoso

Gustavo R. Alves

Maria Teresa Restivo 